\title{
A study on the neuroprotective effect of miR-206-3p on Alzheimer's disease mice by regulating brain-derived neurotrophic factor
}

\author{
Ya Shao ${ }^{1}$, Tianbo $\mathrm{Xu}^{2}$ \\ ${ }^{1}$ Department of Neurology, Gansu Provincial Hospital of Traditional Chinese Medicine, Lanzhou, China; ${ }^{2}$ Department of Neurology, Tiantai \\ County People's Hospital, Taizhou, China \\ Contributions: (I) Conception and design: Y Shao; (II) Administrative support: T Xu; (III) Provision of study materials or patients: Y Shao; (IV) \\ Collection and assembly of data: T Xu; (V) Data analysis and interpretation: Both authors; (VI) Manuscript writing: Both authors; (VII) Final \\ approval of manuscript: Both authors. \\ Correspondence to: Tianbo Xu, BD. Department of Neurology, Tiantai County People's Hospital, No. 1 Kangning Middle Road, Taizhou 317200, \\ China. Email: fnlu959@163.com.
}

Background: Brain-derived neurotrophic factor (BDNF) is involved in the regulation of Alzheimer's disease $(\mathrm{AD})$, but the mechanism is not clear. This study explores the possible mechanism of microRNA206-3p (miR-206-3p) participating in the neuroprotective effect of AD mice by regulating BDNF.

Methods: 36 SPF grade C57 mice were randomly divided into normal group, model group and miR206-3p mimics group (intraperitoneal injection of $3 \mathrm{~mm}$ miR-206-3p mimics) ( $\mathrm{n}=12)$. miR-206-3p mimics group was intervened by miR-206-3p mimics on the basis of AD model. The expression of miR-206-3p was detected by Real time quantitative polymerase chain reaction (qPCR). Zea-Longa score and water maze were used for behavioral detection, he was used to observe the morphology of neurons, and immunohistochemical Western blot was used to detect the expression of BDNF protein, and the targeting relationship between miR-206-3p and BDNF was analyzed.

Results: Compared with the model group, the expression level of miR-206-3p in miR-206-3p mimics group was significantly higher $(\mathrm{P}<0.05)$. compared with the model group, the Zea-Longa score in miR206-3p mimics group was significantly lower $(\mathrm{P}<0.05)$. The escape latency of miR-206-3p mimics group was significantly shorter than that of model group, and the number of crossing the original platform was significantly more than that of model group $(\mathrm{P}<0.05)$. The morphology of neurons in miR-206-3p mimics group was significantly better than that in model group; Immunohistochemistry and Western blot showed that the relative expression of miR-206-3p mimics BDNF protein was significantly increased compared with the model group $(\mathrm{P}<0.05)$. Compared with miR-206-3p control group, the luciferase activity at 3 ' end untranslated area (3' UTR) end of wild-type BDNF in miR-206-3p inhibition group decreased significantly $(\mathrm{P}<0.01)$.

Conclusions: miR-206-3p exerts neuroprotective effects on $\mathrm{AD}$ mouse neurons by up-regulating BDNF.

Keywords: MicroRNA-206-3p (miR-206-3p); Alzheimer's disease (AD); brain-derived neurotrophic factor (BDNF); neurons

Submitted Oct 25, 2021. Accepted for publication Jan 12, 2022.

doi: 10.21037/atm-21-6601

View this article at: https://dx.doi.org/10.21037/atm-21-6601 


\section{Introduction}

Alzheimer's disease (AD), a fairly common neurodegenerative disorder of the central nervous system, frequently occurs in the elderly and mainly impairs memory, cognitive ability and behavior performance, gradually leading to signs of dementia. It is also known as senile dementia $(1,2)$. Studies $(3,4)$ have demonstrated that the morbidity rate of $\mathrm{AD}$ is rising each year. There is also an aging population around the globe. The induced degeneration of memory and cognitive ability seriously affects patients' quality of life and places heavy economic burdens on families and societies.

Brain-derived neurotrophic factor (BDNF) is one of the important members of neurotrophic factor family in the body. It is mainly produced by cerebral cortex and hippocampus, participates in the growth, differentiation and development of neurons, and has a good role in promoting and protecting the nervous system., It is found that the level of BDNF in many patients with nervous system diseases is significantly reduced, and its level is closely related to the learning and memory function of patients; In addition, BDNF is conducive to the survival of neurons in the brain of patients with $\mathrm{AD}$, which is considered to be one of the important targets for the treatment of $\mathrm{AD}(5-7)$. As a kind of non-coding RNA, microRNA plays an important role in the body, especially in regulating a variety of physiological and pathological reactions of cells. As an important non-coding RNA, microRNA-206-3p (miR-206-3p) plays an important role in regulating a variety of downstream substances, and then plays a role in regulating a variety of physiological and pathological reactions $(8,9)$. Previous studies have shown that miR-206-3p has a certain anti dementia effect, but its mechanism is not clear, and whether it can play a certain neuroprotective role in patients with $\mathrm{AD}$ by regulating $\mathrm{BDNF}$ is not clear.

This study sought to investigate the neuroprotective effect of miR-206-3p on AD mice by regulating BDNF. We present the following article in accordance with the ARRIVE reporting checklist (available at https://atm. amegroups.com/article/view/10.21037/atm-21-6601/rc).

\section{Methods}

\section{Laboratory animals}

Thirty-six SPF C57 mice \{license number: SCXK [Shanghai] 2014-0003\} for experiments were purchased from Shanghai SLAC Laboratory Animal Co., Ltd. All the mice were fed a normal diet and sterile filtered water every day at the Laboratory Animal Center under a 12/12 h light/dark cycle and conventional room temperature and humidity. The experiment was carried out according to the project license (No. 2018006) granted by the ethics committee of Gansu Provincial Hospital of Traditional Chinese Medicine, in compliance with Gansu Provincial Hospital of Traditional Chinese Medicine guidelines for the care and use of animals.

\section{Experimental reagents and instruments}

The experimental reagents and instruments included miR206-3p mimics (MCE, USA), amyloid beta-peptide 25-35 (AB25-35) (Sigma, USA), anti-BDNF primary antibody and secondary antibody (Abcam, USA), an immunohistochemistry kit, a hematoxylin-eosin (HE) staining kit and a quantitative polymerase chain reaction (qPCR) kit (Vazyme, Nanjing, China), a light microscope (Leica, Germany), and fluorescence qPCR instrument (ABI, USA).

\section{Animal grouping and processing}

The 36 C57 mice were divided into the normal group $(\mathrm{n}=12)$, model group $(\mathrm{n}=12)$, and miR-206-3p mimics group $(\mathrm{n}=12)$ using a random number table. The experiments were performed after the mice were adaptively fed at the Laboratory Animal Center for $7 \mathrm{~d}$.

The mice in the normal group were raised normally, those in the model group were used to establish the $\mathrm{AD}$ model and then intraperitoneally injected with normal saline, and those in the miR-206-3p mimics group were used to establish the $\mathrm{AD}$ model and then intraperitoneally injected with miR-206-3p mimics ( $3 \mathrm{mM}$ ). Subsequently, specimens were obtained from each group after 3 consecutive weeks of the intervention.

\section{AD modeling}

The $\mathrm{AD}$ mice were intraperitoneally injected with $7 \%$ chloral hydrate $(5 \mathrm{~mL} / \mathrm{kg})$. After successful anesthesia, the mice were fixed on a brain stereotaxic instrument, the drill of the instrument was placed at the hippocampus following local disinfection, and A $25-35$ was injected into a hole drilled on the skull using a micro-syringe to successfully establish the $\mathrm{AD}$ model. 
Table 1 Zea-Longa scores

\begin{tabular}{ll}
\hline Score & Symptom \\
\hline 0 points & No neurological deficits \\
1 point & Mild: unable to completely extend the right forepaw when the tail is lifted \\
2 points & Moderate: circles to right/left when walking \\
3 points & Severe: tumbles to right/left when walking \\
4 points & Unable to walk spontaneously with loss of consciousness \\
\hline
\end{tabular}

\section{Specimen acquisition}

After the mice were anesthetized successfully, blood was collected from the abdominal aorta. Specimens were obtained from 6 mice in each group. Specifically, the brain tissues were directly removed, flushed with normal saline, placed in EP tubes. and stored at $-80{ }^{\circ} \mathrm{C}$ for subsequent Western blotting (WB) and qPCR assays. As for the remaining 6 mice in each group, specimens were collected by means of perfusion-fixation. After fixation with paraformaldehyde, the brain tissues were taken out and fixed with $4 \%$ paraformaldehyde solution for immunohistochemistry and HE staining.

\section{Behavioral examinations}

After the intervention, the neurological deficits of the mice were evaluated via the Zea-Longa score according to the symptoms and manifestations of the mice. The Zea-Longa scores are set out in Table 1. The mice were also placed in a water maze after the last intervention and allowed to move freely. The escape latency time and crossing platform time of the mice in the water maze were recorded. Later, the platform in the water maze was removed, and the mice were placed at any site in the water maze and allowed free movement. Original platform crossing times and residence times in the original quadrant within $70 \mathrm{~s}$ were recorded.

\section{HE staining}

The tissues that had been embedded in paraffin in advance were sliced to $5 \mu \mathrm{m}$-thick sections, spread in $42{ }^{\circ} \mathrm{C}$ warm water, collected, and then baked to prepare the paraffin-embedded tissue sections. The sections were then sequentially immersed in xylene solution and graded alcohol for routine deparaffinization and rehydration. Later, the sections were stained with hematoxylin dye for
5 min using the HE staining kit and placed in pure water for $10 \mathrm{~min}$, followed by color separation with $95 \%$ ethanol for $5 \mathrm{~s}$, transparentization in xylene for $10 \mathrm{~s}$, and mounting in neutral balsam.

\section{Immunobistochemistry}

The tissues that had been embedded in paraffin in advance were sliced to $5 \mu \mathrm{m}$-thick sections, spread in $42{ }^{\circ} \mathrm{C}$ warm water, collected, and then baked to prepare the paraffinembedded tissue sections. The above sections were then placed in xylene solution and gradient alcohol for routine deparaffinization and rehydration. Next, the sections were soaked in citric acid buffer solution and heated repeatedly in a microwave oven 3 times (for $3 \mathrm{~min}$ ) and braised for 5 min each time to achieve adequate antigen retrieval. After rinsing, endogenous peroxidase blocker drops were added to the specimens, which were left to react for $10 \mathrm{~min}$ and sealed in goat serum that was added dropwise for 20 after rinsing. Subsequently, the goat serum was shaken off, and the specimens were incubated with antiBDNF primary antibody $(1: 200)$ in a refrigerator at $4{ }^{\circ} \mathrm{C}$ overnight. The next day, the specimens were rinsed, reacted with a secondary antibody solution that was added in drops for $10 \mathrm{~min}$, rinsed sufficiently again, and then reacted with streptavidin-peroxidase solution for $10 \mathrm{~min}$. Color development with DAB then occurred. The nucleus was counterstained using hematoxylin, and then mounted and observed.

\section{WB assay}

The cardiac tissues that had been preserved at an ultralow temperature were placed in an ice bath to which lysis buffer had been added for $1 \mathrm{~h}$, and centrifuged at $14,000 \mathrm{~g}$ for $10 \mathrm{~min}$. Later, the protein was quantified using the BCA method, and the protein concentration 
Table 2 Primer sequences

\begin{tabular}{ll}
\hline Name & Primer sequence \\
\hline miR-206-3p & Forward primer: 5'-TTGGGGTTAGGTTTGGGTTTTAC-3' \\
& Reverse primer: 5'-CGTAAACGAAATTCGACCCCACTA-3' \\
GADPH & Forward primer: 5'-ACGGCAAGTTCAACGGCACAG-3' \\
& Reverse primer: 5'-GAAGACGCCAGTAGACTCCACGAC-3' \\
\hline
\end{tabular}

miR-206-3p, microRNA-206-3p; GADPH, glyceraldehyde 3-phosphate dehydrogenase.

of the tissues was calculated based on the absorbance and standard curve obtained from a microplate reader. Subsequently, the proteins in the tissue specimens were denatured and then separated via sodium dodecyl sulfate polyacrylamide gel electrophoresis, which was terminated when the marker proteins reached the bottom of the glass plate in a straight line. Next, the proteins were transferred onto a polyvinylidene fluoride membrane and sealed in blocking buffer for $1.5 \mathrm{~h}$, after which anti-BDNF primary antibody $(1: 1,000)$ and secondary antibody $(1: 1,000)$ were sequentially added. Finally, the images were developed using chemiluminescent reagent in the dark for $1 \mathrm{~min}$ after rinsing.

\section{qPCR assay}

RNA extraction reagent was added to the cardiac tissues, which had been stored for use, to extract the total RNA in the specimens. Next, the total RNA extracted was reverse transcribed into complementary DNA (cDNA) using a reverse transcription kit and a $20 \mu \mathrm{L}$ reaction system. Reaction conditions: reaction at $53{ }^{\circ} \mathrm{C}$ for $5 \mathrm{~min}$, predenaturation at $95{ }^{\circ} \mathrm{C}$ for $10 \mathrm{~min}$, denaturation at $95{ }^{\circ} \mathrm{C}$ for $10 \mathrm{~s}$, and annealing at $62{ }^{\circ} \mathrm{C}$ for $30 \mathrm{~s} ; 35$ cycles in total. The $\Delta \mathrm{Ct}$ value was first calculated, and the difference in the expression of the target genes was then calculated. The detailed primer sequences are shown in Table 2.

\section{Luciferase reporter assay}

BV2 microglia were cultured to construct the $3^{\prime}$ end untranslated area (3' UTR) region wild-type reporter gene plasmid of BDNF gene and the mutant gene reporter plasmid of miR-206-3p binding site with BDNF region. At the same time, miR-206-3p control and miR-206-3p inhibition were transfected and cultured for 24 hours to detect its luciferase activity. Each group is provided with 6 multiple holes.

\section{Statistical methods}

In this study, SPSS 20.0 software was used for the statistical analysis. The enumeration data are presented as mean \pm standard deviation. The data that had a normal distribution and homogeneity of variance were tested using a $t$-test. The data that had a normal distribution and heterogeneity of variance were tested using a corrected $t$-test. The data that did not have a normal distribution and homogeneity of variance were tested using a non-parametric test. The ranksum test was used for the ranked data. The chi-square test was used for the enumeration data.

\section{Results}

\section{miR-206-3p expression}

Compared with the normal group, the expression of miR206-3p in the model group decreased significantly $(\mathrm{P}<0.05)$; compared with the model group, the expression level of miR-206-3p in the miR-206-3p mimics group increased significantly $(\mathrm{P}<0.05)$ (see Table 3$)$.

\section{Zea-Longa scores}

The Zea-Longa score was the lowest in the normal group and the highest in the model group (see Figure 1). Additionally, the Zea-Longa score in the model group and miR-206-3p mimics group was significantly increased compared to that of the normal group $(\mathrm{P}<0.05)$. Conversely, it was significantly decreased in the miR-206-3p mimics group compared to that of the model group $(\mathrm{P}<0.05)$.

\section{Water maze test}

As Figure 2 shows, the model group and miR-206-3p mimics group had a significantly longer escape latency time and took significantly fewer times to cross the original platform than the normal group $(\mathrm{P}<0.05)$. Additionally, 
Table 3 expression of miR-206-3p in each group $\left(\bar{x}_{ \pm s}\right)$

\begin{tabular}{lcc}
\hline Grouping & $\mathrm{N}$ & $\mathrm{miR-206-3p}$ \\
\hline Normal group & 12 & $3.39 \pm 0.86$ \\
Model group & 12 & $1.62 \pm 0.58^{\star}$ \\
miR-206-3p mimics group & 12 & $2.29 \pm 0.63^{\#}$ \\
F & - & 19.520 \\
P & - & $<0.001$ \\
\hline
\end{tabular}

${ }^{*} \mathrm{P}<0.05$ vs. normal group; ${ }^{\#} \mathrm{P}<0.05$ vs. model group. miR-206-3p, microRNA-206-3p.

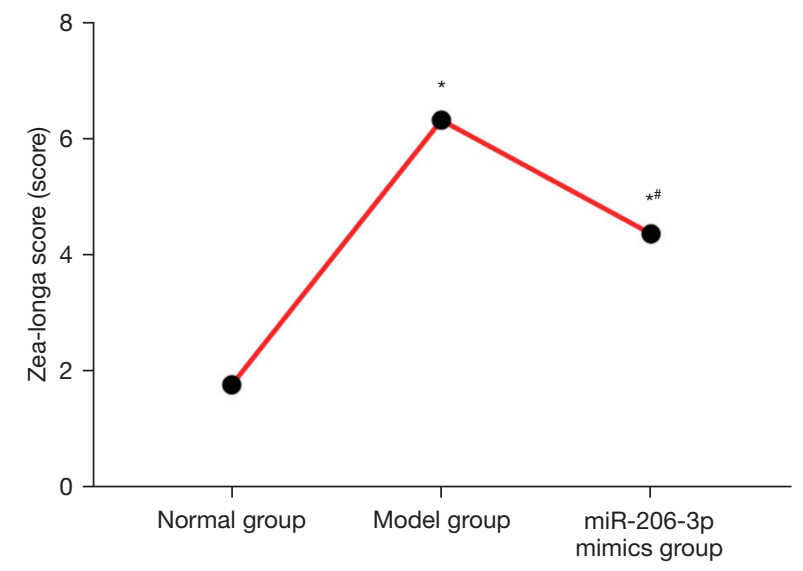

Figure 1 Zea-Longa scores for each group. ${ }^{*} \mathrm{P}<0.05$ vs. normal group; ${ }^{\mathrm{P}<0.05}$ vs. model group. miR-206-3p, microRNA-206-3p.

the miR-206-3p mimics group had a significantly shorter escape latency time and took significantly more times crossing the original platform than the model group $(\mathrm{P}<0.05)$.

\section{HE staining}

In the normal group, the neuronal morphology was normal and there was a large number of Nissl bodies. In the model group, the neurons were damaged and the Nissl bodies were decomposed. However, the neuronal morphology was improved in the miR-206-3p mimics group (see Figure 3).

\section{Immunobistochemistry}

As Figure $4 A$ shows, the positive expression of BDNF was low in the normal group but high in the other groups. The statistical results (see Figure $4 B$ ) revealed that the average optical density of the positive expression of BDNF was
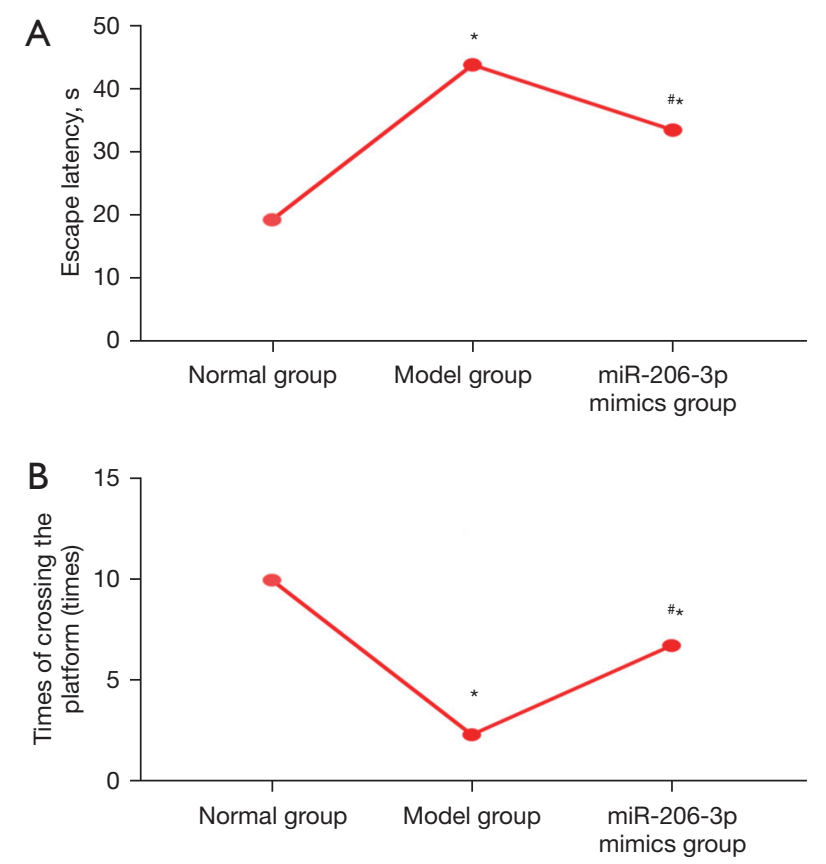

Figure 2 Water maze test results for each group of mice. (A) Escape latency times for each group; (B) platform crossing times for each group. ${ }^{*} \mathrm{P}<0.05$ vs. normal group; ${ }^{\#} \mathrm{P}<0.05$ vs. model group. miR-206-3p, microRNA-206-3p.

significantly higher in the model group and miR-206$3 \mathrm{p}$ mimics group than the normal group $(\mathrm{P}<0.05)$, and significantly higher in the miR-206-3p mimics group than the model group $(\mathrm{P}<0.05)$.

\section{Expression of relevant proteins determined via WB assay}

As Figure $5 A$ shows, there were few protein expressions of BDNF in the normal group and there were more protein expressions of BDNF in the other groups. The statistical results (see Figure 5B) showed that the relative protein 

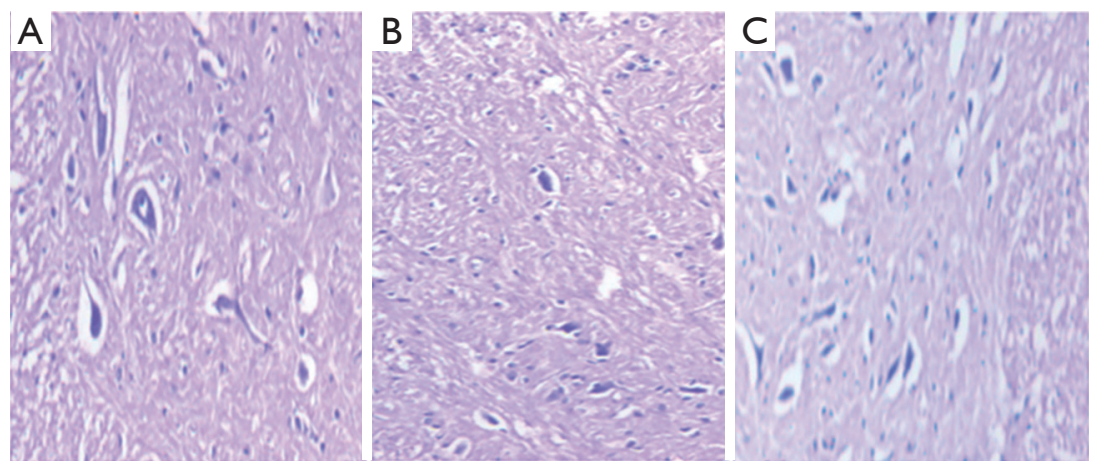

Figure 3 Neuronal morphology observed via HE staining (×200). (A) Normal group; (B) model group; (C) miR-206-3p mimics group. HE, hematoxylin-eosin; miR-206-3p, microRNA-206-3p.
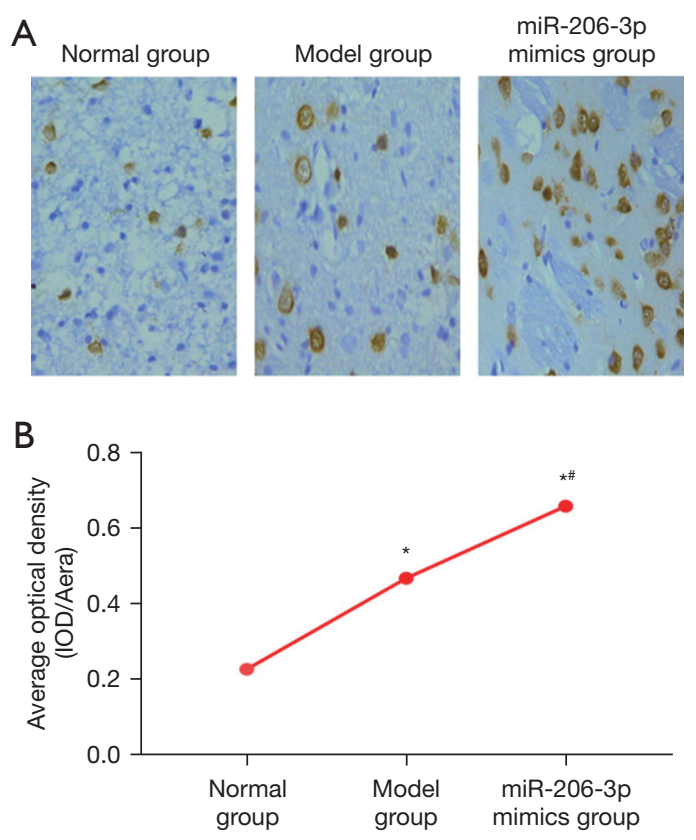

Figure 4 BDNF expression detected via immunohistochemistry. (A; $\times 200)$ Positive expression of BDNF detected via immunohistochemistry; (B) average optical density of the positive expression of $\mathrm{BDNF}$ for each group. ${ }^{*} \mathrm{P}<0.05$ vs. normal group; ${ }^{\#} \mathrm{P}<0.05$ vs. model group. BDNF, brain-derived neurotrophic factor; miR-206-3p, microRNA-206-3p; IOD, integrated optical density.

expression of BDNF was significantly more increased in the model group and miR-206-3p mimics group than the normal group $(\mathrm{P}<0.05)$. Further, the relative protein expression of BDNF was also significantly more increased in the miR-206-3p mimics group than the model group $(\mathrm{P}<0.05)$.
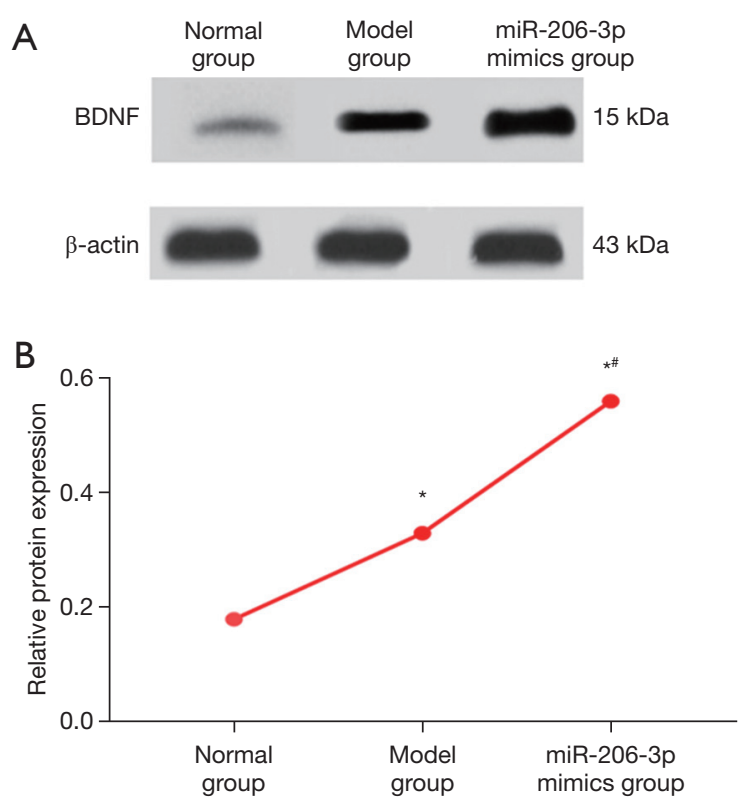

Figure 5 Protein expression of BDNF determined via WB assay. (A) Protein expression of BDNF detected via WB assay; (B) relative protein expression of $\mathrm{BDNF}$ for each group. ${ }^{*} \mathrm{P}<0.05$ vs. normal group; ${ }^{\#} \mathrm{P}<0.05$ vs. model group. BDNF, brain-derived neurotrophic factor; WB, Western blotting; miR-206-3p, microRNA-206-3p.

\section{$m R N A$ expression examined by $q P C R$ assay}

As Figure 6 shows, the model group and miR-206-3p mimics group had a significantly higher expression level of $\mathrm{miR}-206-3 \mathrm{p}$ than the normal group $(\mathrm{P}<0.05)$. Finally, the miR-206-3p mimics group had a significantly higher relative expression level of miR-206-3p than the model $(\mathrm{P}<0.05)$. 


\section{Luciferase activity expression}

Compared with miR-206-3p control group, the luciferase activity at 3' UTR end of wild-type BDNF in miR-206-3p inhibition group decreased significantly $(\mathrm{P}<0.01)$; there was no significant difference in luciferase activity at 3' UTR end of mutant BDNF between the two groups $(\mathrm{P}>0.05)$ (See Table 4).

\section{Discussion}

As a relatively common neurodegenerative disorder of the central nervous system in clinic, $\mathrm{AD}$ is characterized by chronic progressive cognitive and memory impairment, and changes in personality behavior. Studies (10-12) have shown that the incidence rate of $\mathrm{AD}$ is increasing each year, and the disease is highly prevalent among elderly people. However, as the pathogenesis of $\mathrm{AD}$ is very complex and unclear, it is crucial to seek an efficacious therapeutic method for $\mathrm{AD}$ to improve the memory, cognitive ability,

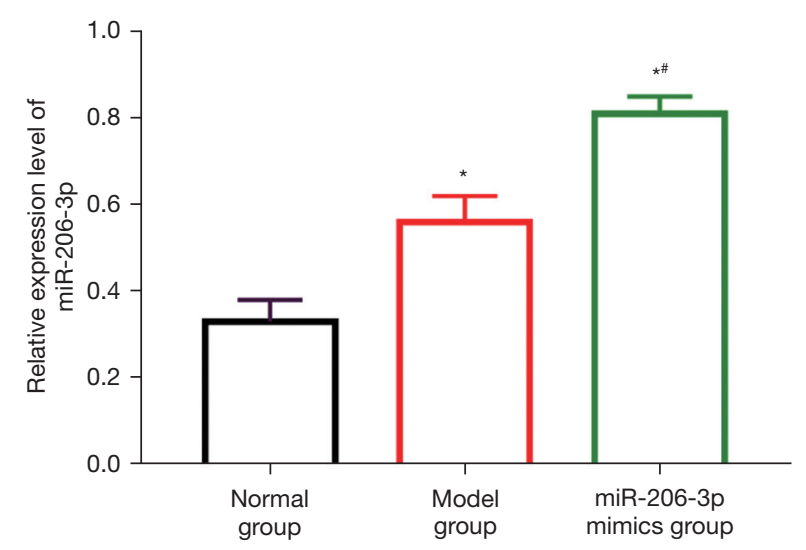

Figure 6 Relative expression level of miR-206-3p for each group. ${ }^{*} \mathrm{P}<0.05$ vs. normal group; ${ }^{\#} \mathrm{P}<0.05$ vs. model group. miR-206-3p, microRNA-206-3p. and personality behavior of $\mathrm{AD}$ patients. Neuronal damage is currently thought to be a key pathological response in the pathogenesis of $\mathrm{AD}(3,4,13-16)$. Various factors may lead to neuronal damage in the brain, including neuroinflammation, apoptosis, and $\mathrm{A} \beta$ accumulation, which can cause a series of pathological changes, such as necrosis and axonal demyelination by inducing neuronal damage, thus affecting the repair of the nervous system after damage and triggering changes in the memory, cognitive ability, and personality behavior of patients. Hence, restoring neuronal damage in the course of $\mathrm{AD}$ and protecting neurons are important to the treatment of $\mathrm{AD}$.

BDNF, a vital member of the neurotrophin family of organisms, plays crucial roles in promoting neuron repair, facilitating neuron regeneration, and ameliorating axonal repair. Research (17-20) has shown that exogenous BDNF can effectively accelerate neuron regeneration and repair at the site of a central nervous system injury, exerting important neuroprotective effects. As a category of noncoding RNAs, miRNAs have vital roles in regulating multiple downstream signaling pathways and substance expressions in the body and participate in a variety of physiological and pathological responses. miR-206-3p, an essential member of the miRNA family, also controls the expressions of many downstream proteins and genes and plays crucial physiological and pathological roles.

In this study, we found that BNDF was highly expressed in the brain tissues of $\mathrm{AD}$ mice and involved in the protective effect on neurons. Similarly, miR-206-3p was highly expressed in the brain tissues of $\mathrm{AD}$ mice. Thus, miR-206-3p appears to be involved in the regulation of $\mathrm{BDNF}$ after the onset of $\mathrm{AD}$, thereby protecting neurons. In addition, exogenous miR-206-3p further enhances the BDNF expression, ameliorates the neuronal morphology, and improves the cognitive ability and memory of $\mathrm{AD}$ mice. Thus, miR-206-3p exerts a neuroprotective effect on the neurons of $\mathrm{AD}$ mice by upregulating BDNF.

Table 4 Luciferase activity of miR-206-3p and 3' UTR end of BDNF detected by double luciferase report experiment $(\bar{x} \pm \mathrm{s})$

\begin{tabular}{lccc}
\hline Grouping & $\mathrm{N}$ & Wild type & Mutant \\
\hline miR-206-3p control & 6 & $1.00 \pm 0.05$ & $1.01 \pm 0.15$ \\
miR-206-3p inhibition & 6 & $0.47 \pm 0.08$ & $1.07 \pm 0.06$ \\
$\mathrm{t}$ & - & 13.761 & 0.910 \\
$\mathrm{P}$ & - & $<0.001$ & 0.384 \\
\hline
\end{tabular}

miR-206-3p, microRNA-206-3p; 3' UTR, 3' end untranslated area; BDNF, brain-derived neurotrophic factor. 


\section{Acknowledgments}

Funding: None.

\section{Footnote}

Reporting Checklist: The authors have completed the ARRIVE reporting checklist. Available at https://atm. amegroups.com/article/view/10.21037/atm-21-6601/rc

Data Sharing Statement: Available at https://atm.amegroups. com/article/view/10.21037/atm-21-6601/dss

Conflicts of Interest: Both authors have completed the ICMJE uniform disclosure form (available at https://atm. amegroups.com/article/view/10.21037/atm-21-6601/coif). The authors have no conflicts of interest to declare.

Ethical Statement: The authors are accountable for all aspects of the work in ensuring that questions related to the accuracy or integrity of any part of the work are appropriately investigated and resolved. The experiment was carried out according to the project license (No. 2018006) granted by the ethics committee of Gansu Provincial Hospital of Traditional Chinese Medicine, in compliance with Gansu Provincial Hospital of traditional Chinese Medicine guidelines for the care and use of animals.

Open Access Statement: This is an Open Access article distributed in accordance with the Creative Commons Attribution-NonCommercial-NoDerivs 4.0 International License (CC BY-NC-ND 4.0), which permits the noncommercial replication and distribution of the article with the strict proviso that no changes or edits are made and the original work is properly cited (including links to both the formal publication through the relevant DOI and the license). See: https://creativecommons.org/licenses/by-nc-nd/4.0/.

\section{References}

1. McKhann GM, Knopman DS, Chertkow H, et al. The diagnosis of dementia due to Alzheimer's disease: recommendations from the National Institute on AgingAlzheimer's Association workgroups on diagnostic guidelines for Alzheimer's disease. Alzheimers Dement 2011;7:263-9.

2. Ballard C, Gauthier S, Corbett A, et al. Alzheimer's disease. Lancet 2011;377:1019-31.

3. Rovio S, Kåreholt I, Helkala EL, et al. Leisure-time physical activity at midlife and the risk of dementia and Alzheimer's disease. Lancet Neurol 2005;4:705-11.

4. Hardy J. The amyloid hypothesis for Alzheimer's disease: a critical reappraisal. J Neurochem 2009;110:1129-34.

5. Zhang L, Fang Y, Zeng Z, et al. BDNF gene polymorphisms are associated with Alzheimer's diseaserelated depression and antidepressant response. J Alzheimers Dis 2011;26:523-30.

6. Hsiao YH, Hung HC, Chen SH, et al. Social interaction rescues memory deficit in an animal model of Alzheimer's disease by increasing BDNF-dependent hippocampal neurogenesis. J Neurosci 2014;34:16207-19.

7. Chang L, Wang Y, Ji H, et al. Elevation of peripheral BDNF promoter methylation links to the risk of Alzheimer's disease. PLoS One 2014;9:e110773.

8. Mu Y, Zhou H, Wu WJ, et al. Dynamic expression of miR-206-3p during mouse skin development is independent of keratinocyte differentiation. Mol Med Rep 2015;12:8113-20.

9. Tang R, Ma F, Li W, et al. miR-206-3p Inhibits 3T3-L1 Cell Adipogenesis via the c-Met/PI3K/Akt Pathway. Int J Mol Sci 2017;18:1510.

10. Weiner HL, Lemere CA, Maron R, et al. Nasal administration of amyloid-beta peptide decreases cerebral amyloid burden in a mouse model of Alzheimer's disease. Ann Neurol 2000;48:567-79.

11. Small DH, Mok SS, Bornstein JC. Alzheimer's disease and Abeta toxicity: from top to bottom. Nat Rev Neurosci 2001;2:595-8.

12. Geldmacher DS, Provenzano G, McRae T, et al. Donepezil is associated with delayed nursing home placement in patients with Alzheimer's disease. J Am Geriatr Soc 2003;51:937-44.

13. Thibault O, Gant JC, Landfield PW. Expansion of the calcium hypothesis of brain aging and Alzheimer's disease: minding the store. Aging Cell 2007;6:307-17.

14. Doody RS, Raman R, Farlow M, et al. A phase 3 trial of semagacestat for treatment of Alzheimer's disease. N Engl J Med 2013;369:341-50.

15. Migliorelli R, Tesón A, Sabe L, et al. Prevalence and correlates of dysthymia and major depression among patients with Alzheimer's disease. Am J Psychiatry 1995;152:37-44.

16. Mrak RE, Griffin WS. Interleukin-1, neuroinflammation, and Alzheimer's disease. Neurobiol Aging 2001;22:903-8.

17. Zdanys KF, Kleiman TG, Zhang H, et al. BDNF 
variants, premorbid educational attainment, and disease characteristics in Alzheimer's disease: an exploratory study. J Alzheimers Dis 2009;17:887-98.

18. Peng S, Wuu J, Mufson EJ, et al. Precursor form of brainderived neurotrophic factor and mature brain-derived neurotrophic factor are decreased in the pre-clinical stages of Alzheimer's disease. J Neurochem 2005;93:1412-21.

19. Putzke JD, Uitti RJ, Obwegeser AA, et al. Bilateral thalamic deep brain stimulation: midline tremor control. J

Cite this article as: Shao $\mathrm{Y}, \mathrm{Xu} \mathrm{T}$. A study on the neuroprotective effect of miR-206-3p on Alzheimer's disease mice by regulating brain-derived neurotrophic factor. Ann Transl Med 2022;10(2):85. doi: 10.21037/atm-21-6601
Neurol Neurosurg Psychiatry 2005;76:684-90.

20. Desai P, Nebes R, DeKosky ST, et al. Investigation of the effect of brain-derived neurotrophic factor (BDNF) polymorphisms on the risk of late-onset Alzheimer's disease $(\mathrm{AD})$ and quantitative measures of $\mathrm{AD}$ progression. Neurosci Lett 2005;379:229-34.

(English Language Editor: L. Huleatt) 